\title{
IDENTIFIKASI LAPISAN AKUIFER TERTEKAN DENGAN METODE GEOLISTRIK DI DESA LOK RAWA KECAMATAN MANDASTANA KABUPATEN BARITO KUALA KALIMANTAN SELATAN
}

\author{
Samsul Anwar*, Sri Cahyo Wahyono, Fahruddin \\ Program Studi Fisika Fakultas Matematika dan Ilmu Pengetahuan Alam \\ Universitas Lambung Mangkurat \\ e-mail : *anwarsyamfisika123@gmail.com
}

Diterima (22 Januari 2020), Direvisi (24 Juni 2020)

\begin{abstract}
One way to be able to identify rocks below the surface, depth, including groundwater aquifer layers is to do geophysical measurements using the schlumberger geoelectric method. This study aims to determine thickness and depth of aquifers in Lok Rawa Village, Mandastana District, Barito Kuala Regency. The results of the schlumberger configuration geoelectric study showed rock layers in Lok Rawa Village at the measurement points GL1, GL2 and GL3 consisting of weathered, sand, and fine clay (silt) layers. Lapiasan aquifers in Lok Rawa Village at the measurement points GL1, GL2 and GL3 consisting of free aquifer layers are estimated to occur at a depth of 3-5 $\mathrm{m}$ with a resistivity value of 7-15 $\Omega \mathrm{m}$. Depressed aquifer layer is estimated to be at a depth of $25-75 \mathrm{~m}$ and $\geq 110 \mathrm{~m}$ with resistivity values of $7-15 \Omega \mathrm{m}$. Of the 2 types of aquifer layers, the most confined aquifer layer has the potential to contain ground water.
\end{abstract}

Keywords: geoelectric, Schlumberger configuration, aquifer.

\begin{abstract}
Abstrak. Salah satu cara untuk dapat mengidentifikasi batuan di bawah permukaan, kedalaman, termasuk lapisan akuifer airtanah adalah dengan melakukan pengukuran geofisika dengan menggunakan metode geolistrik schlumberger. Penelitian ini bertujuan untuk mengetahui ketebalan dan kedalaman akuifer di Desa Lok Rawa Kecamatan Mandastana Kabupaten Barito Kuala. Hasil studi geolistrik konfigurasi schlumberger menunjukkan lapisan batuan di Desa Lok Rawa pada titik pengukuran GL1, GL2 dan GL3 yang terdiri dari lapisan lapuk, pasir, dan lempung halus (lanau). Akuifer Lapiasan di Desa Lok Rawa di titik pengukuran GL1, GL2 dan GL3 yang terdiri dari lapisan akuifer bebas diperkirakan terjadi pada kedalaman 3-5 m dengan nilai resistivitas $7-15 \Omega \mathrm{m}$. Lapisan akuifer tertekan diperkirakan berada pada kedalaman $25-75 \mathrm{~m}$ dan $\geq 110 \mathrm{~m}$ dengan nilai resistivitas $7-15 \Omega \mathrm{m}$. Dari 2 jenis lapisan akuifer tersebut, lapisan akuifer tertekan paling banyak berpotensi menampung air tanah.
\end{abstract}

Kata kunci: geolistrik, konfigurasi Schlumberger, akuifer.

\section{PENDAHULUAN}

Akuifer merupakan lapisan bawah permukaan tanah yang dapat menyimpan dan mengalirkan air. Akuifer terbagi atas 4 macam tetapi yang dianalisa 1 macam yaitu akuifer tertekan. Akuifer tertekan (confined aquifer) adalah lapisan air tanah yang jumlah airnya di batasi oleh lapisan kedap air, baik di atas maupun di bawah dan mempunyai tekanan jenuh lebih besar daripada tekanan atmosfer. Kemudian untuk pembuatan sumur bor sebaiknya terletak di 
lapisan akuifer tertekan karena lapisan ini mengandungan air lebih bagus dan lapisannya lebih tebal. [1].

Penelitian Hanifa dkk (2016) [2] mengenai akuifer tanah dengan metode geolistrik Konfigurasi Schlumberger di mataram, menunujukkan bahwa nilai resistivitas 100-450 $\Omega \mathrm{m}$ sebagai lapisan batu pasir dan diduga mengandung air tanah. Kemudian penelitian Usman dkk (2017) [3] mengenai identifikasi akuifer air tanah di kota polopo menunjukkan nilai resistivitas 11,6-81,3 $\Omega \mathrm{m}$ sebagai pasir dan kerikil dengan kedalaman lebih dari $45 \mathrm{~m}$. Kemudian penelitian Winarni dkk (2014) tentang identifikasi akuifer air tanah di kabupaten sragen menunjukkan nilai resistivitas 14,3-83,4 $\Omega \mathrm{m}$ sebagai pasir dan pasir berlempung diduga sebagai akuifer. Berdasarkan hasil penelitian tersebut maka penelitian akuifer tertekan menggunakan metode geolistrik dengan konfigurasi schlumberger sangat mungkin dilakukan dan memberikan hasil yang baik[2][3][4].

Penelitian ini telah dilakukan di Desa Lok Rawa Kecamatan Mandastana Kabupaten Barito Kuala Kalimantan Selatan yang direncanakan akan dibangun sumur bor. Penelitian ini dibatasi dengan menentukan lapisan litologi berdasarkan nilai resistivitas, kedalaman dan ketebalan lapisan akuifer menggunakan metode geolistrik resistivitas konfigurasi schlumberger dengan pengolahan data menggunakan software progress dan softwere IPI2win untuk menentukan lapisan akuifer tertekan.

\section{Metode Geolistrik}

Proses metode geolistrik dilakukan dengan cara menginjeksikan arus listrik ke permukaan tanah melalui sepasang elektroda dan mengukur beda potensial dengan sepasang elektroda yang lain dalam suatu susunan atau konfigurasi tertentu. Metode ini juga bisa digunakan untuk mengetahui adanya air tanah dan eksplorasi mineral. Peralatan yang harus dimiliki dalam pengukuran metode geolistrik resistivitas antara lain sumber arus dan alat pengukur untuk potensial arus serta elektroda yang digunakan untuk memasukkan arus ke dalam bumi [5].

Adapun harga resistivitas listrik suatu formasi di bawah permukaan ditentukan menurut persamaan (1):

$$
\rho=K \frac{\Delta V}{I}
$$

Keterangan:

$\mathrm{K}=$ Faktor geometri (m)

$\Delta \mathrm{V}=$ Beda potensial yang diperoleh dari pengukuran (Volt)

I = Arus yang diinjeksikan ke dalam bumi (Ampere) (Reynold, 1997).

dengan $\mathrm{K}$ adalah faktor geometri tergantung pada penempatan elektroda di permukaan ditentukan menurut persamaan (2) [6]:

$$
\mathrm{K}=\pi\left(\frac{\mathrm{b}^{2}}{\mathrm{a}}-\frac{\mathrm{a}}{4}\right)
$$

\section{Konfigurasi Schlumberger}

Konfigurasi schlumberger adalah konfigurasi yang membutuhkan tempat yang luas. Konfigurasi ini tersusun dari dua elektroda arus dan dua elektroda potensial. Elektroda potensial ditempatkan pada bagian dalam dan elektroda arus pada bagian luar. Pengukuran dilakukan dengan memindahkan elektroda arus lebih sering dengan ketentuan yang ada, dan potensial lebih dominan standbai tidak secara bersamaan [7].

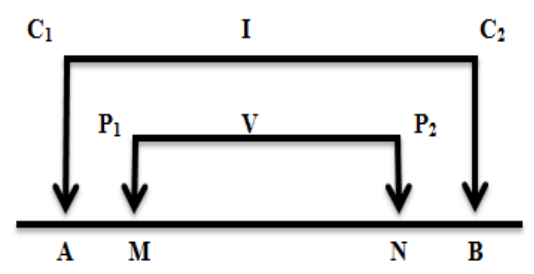

Gambar 1. Konfigurasi Schlumberger. 


\section{METODE PENELITIAN}

\section{Alat}

Alat dan bahan yang digunakan dalam penelitan ini adalah sebagai berikut:

1. Seperangkat Resistivity meter OYO McOHM 2119EL, sebagai alat untuk melakukan pengukuran resistivitas batuan.

2. Kabel arus dan potensial, berfungsi sebagai penghantar arus pada elektroda.

3. Elektroda arus dan potensial, berfungsi sebagai penghantar arus dari sumber ke batuan.

4. Palu, berfungsi sebagai alat untuk memukul elektroda.

5. GPS (global positioning system), untuk menentukan titik koordinat daerah penelitian.

6. Aki 12 volt, berfungsi sebagai sumber tegangan.

7. HT (handy talky), berfungsi sebagai alat komunikasi selama pengukuran.

8. Laptop, berfungsi sebagai hardware yang digunakan untuk mengolah data.
9. Software pengolahan data geolistrik yaitu software IPI2win dan Softwere Progress.

\section{Tahapan Penelitian}

1. Survey lapangan, sebagai langkah awal untuk mengetahui kondisi lingkungan di daerah penelitian.

2. Akuisisi data lapangan menggunakan metode geolistrik konfigurasi schlumberger yang memiliki susunan elektroda $\mathrm{C}_{1}, \mathrm{P}_{1}, \mathrm{P}_{2}, \mathrm{C}_{2}$.

3. Analisa data, data yang didapat berupa nilai resistivitas dari tiap-tiap titik pengukuran yang terukur.

4. Interpretasi data, hasil berupa lapisan litologi, ketebalan dan kedalaman akuifer

\section{Prosedur Penelitian}

Prosedur penelitian dapat dilihat pada gambar berikut:

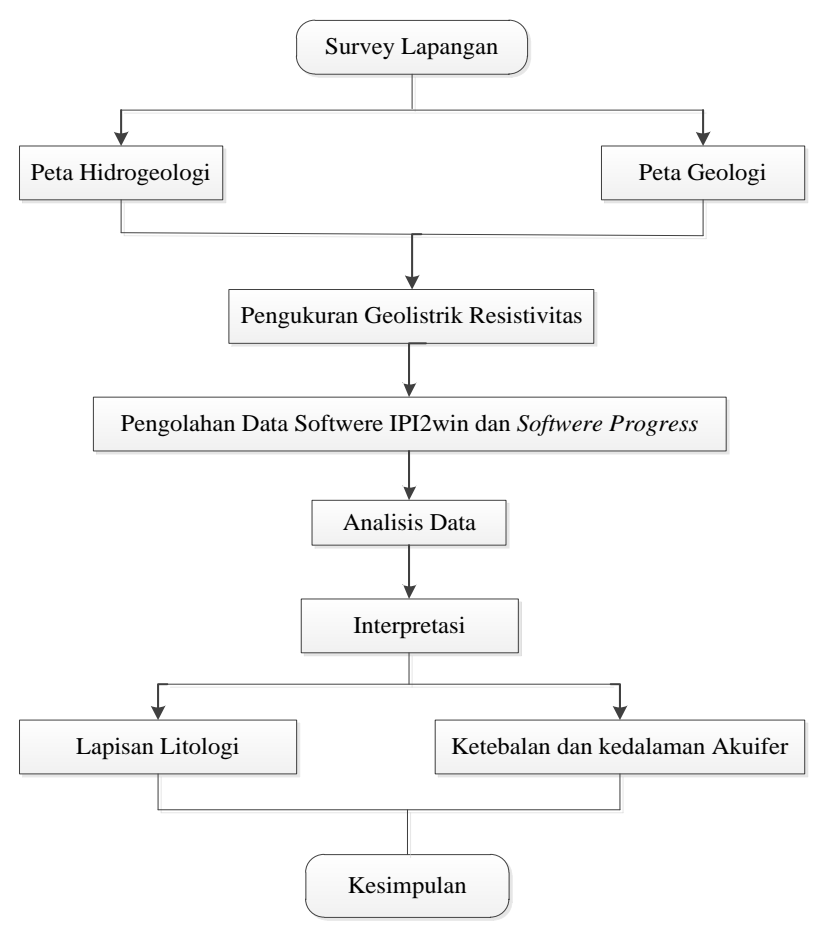

Gambar 2. Diagram alir 


\section{HASIL DAN PEMBAHASAN}

Hasil interpretasi pendugaan geolistrik adapun jumlah lapisan, kedalaman, ketebalan berdasarkan nilai tahanan jenis, perkiraan lithology dan hidrogeologi terhadap air bawah tanah terdapat pada Tabel 1. Berdasarkan tabel hasil interpretasi GL1 tersebut dapat diperkirakan struktur lapisan batuannya terdiri dari lapisan lapuk dengan nilai resistivitas $76,14 \Omega \mathrm{m}$ pada kedalaman $0,00-1,1 \mathrm{~m}$ dan tebalnya $1,1 \mathrm{~m}$, lapisan selanjutnya adalah lempung halus (silt) dengan nilai resistivitas $1,55 \Omega \mathrm{m}$ pada kedalaman 1,10-6,01 $\mathrm{m}$ dan tebalnya 4,91 $\mathrm{m}$, pasir dengan nilai resistivitas $37,5 \Omega \mathrm{m}$ pada kedalaman 6,01-16,72 $\mathrm{m}$ dan tebalnya $10,71 \mathrm{~m}$ yang diduga sebagai akuifer tertekan yang dapat menyimpan dan mengalirkan air tanah, lempung halus (silt) dengan nilai resistivitas $0,9 \Omega \mathrm{m}$ pada kedalaman 16,72-129,04 $\mathrm{m}$ dengan ketebalan $112,32 \mathrm{~m}$, dan pasir dengan nilai resistivitas $89,11 \Omega \mathrm{m}$ pada kedalaman $\geq 129,04 \mathrm{~m}$ yang diduga sebagai lapisan akuifer. Pada lapisan akuifer tertekan yang baik untuk sumur bor karena tekanan airnya besar dan kandungan airnya baik [8].

Hasil interpretasi GL2 diperkirakan struktur lapisan batuan bawah tanah terdiri dari lapisan lapuk dengan nilai resistivitas $16,51 \Omega \mathrm{m}$ pada kedalaman $0,00-2,17 \mathrm{~m}$ dan tebalnya 2,17 m, lempung halus (silt) dengan nilai resistivitas $0.02 \Omega \mathrm{m}$ pada kedalaman 2,17-2,28 $\mathrm{m}$ dan tebalnya $0,11 \mathrm{~m}$, pasir dengan nilai resistivitas $34,35 \Omega \mathrm{m}$ pada kedalaman 2,28-16,72 $\mathrm{m}$ dan tebalnya $14,44 \mathrm{~m}$ yang diduga sebagai lapisan akuifer tertekan dan baik untuk sumur bor pada kedalaman ini, lempung halus (silt) dengan nilai resistivitas $0,16 \Omega \mathrm{m}$ pada kedalaman $16,72-141,70 \mathrm{~m}$ dan tebalnya $124,98 \mathrm{~m}$, dan pasir dengan nilai resistivitas $36,05 \Omega \mathrm{m}$ pada kedalaman $\geq 141,70 \mathrm{~m} \mathrm{[9]}$.

Hasil interpretasi GL3 diperkirakan struktur lapisan batuan bawah tanah terdiri dari lapisan lapuk dengan nilai resistivitas $81,07 \Omega \mathrm{m}$ pada kedalaman $0,00-1,07 \mathrm{~m}$ dan tebalnya $1,07 \mathrm{~m}$, lempung halus (silt) dengan nilai resistivitas $3,71 \Omega \mathrm{m}$ pada kedalaman 1,07-5,53 $\mathrm{m}$ dan tebalnya 4,46 $\mathrm{m}$, lempung halus (silt) dengan nilai resistivitas $0,84 \Omega \mathrm{m}$ pada kedalaman 5,53-21,56 $\mathrm{m}$ dan tebalnya $16,01 \mathrm{~m}$, pasir dengan nilai resistivitas $38,76 \Omega \mathrm{m}$ pada kedalaman 21,56-107,17 $\mathrm{m}$ dan tebalnya $85,59 \mathrm{~m}$, dan pasir dengan nilai resistivitas $160,83 \Omega \mathrm{m}$ pada kedalaman $\geq 107,17 \mathrm{~m}$. Lapisan yang mengandung pasir yang baik untuk menyimpan air tanah dan mengalirkanya. Lapisan ini yang baik untuk sumur bor karena sebagai akuifer [8] dan [10].

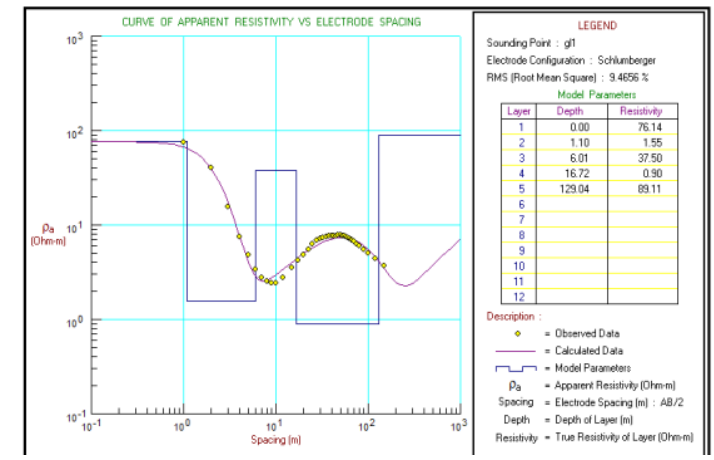

Gambar 3. Hasil interpretasi GL1 dengan softwere progress.

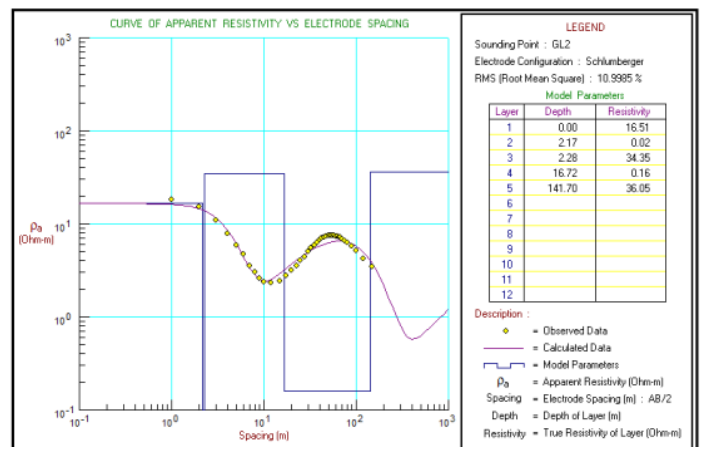

Gambar 4. Hasil interpretasi GL2 dengan softwere progress 


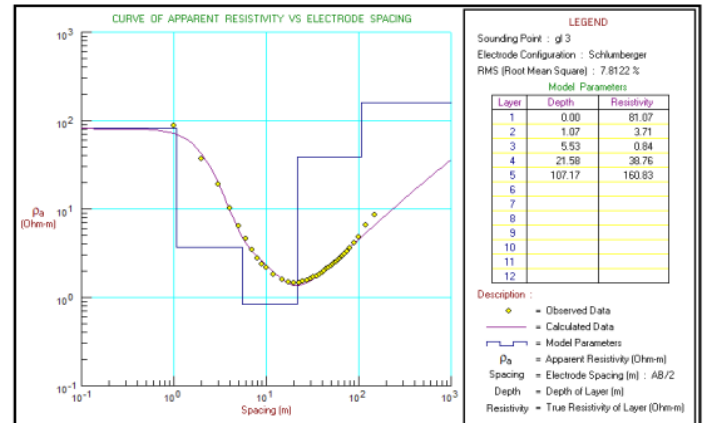

Gambar 5. Hasil interpretasi GL.3 dengan softwere progress

Hasil interpretasi gabungan GL1, GL2 dan GL3 dengan Softwere IPI2win diperoleh citra pada perlapisan warna, sumbu vertikal mewakili kedalaman (m) dan citra berwarna mewakili besarnya resistivitas $(\Omega \mathrm{m})$. Lapisan paling atas dengan citra warna merah muda sampai kuning merupakan lapisan lapuk bersifat kering dan tidak berpotensi ada air karena memiliki nilai resistivitas $16-100 \Omega \mathrm{m}$. Lapisan selanjutnya yang berwarna hijau sampai ke abu-abu merupakan lapisan lempung berpasir yang bersifat sebagai akuifer yang dapat menyimpan air dan mengalirkan air dengan nilai resitivitas 7-15 $\Omega \mathrm{m}$. Lapisan berwarna biru sampai hitam merupakan lapisan lempung dan lanau yang dapat menyimpan dan tidak dapat mengalirkan air dengan nilai resistivitas $1-6$ $\Omega \mathrm{m}[9]$.

Berdasarkan hasil interpretasi gabungan diproleh dua jenis akuifer yaitu akuifer bebas dan akuifer tertekan. Akuifer bebas terdapat pada kedalaman 3-5 m dengan nilai resistivitas 7-15 $\Omega \mathrm{m}$ dengan citra warna hijau. akuifer tertekan terdapat pada kedalaman $25-75 \mathrm{~m}$, tebalnya $50 \mathrm{~m}$, di lintasn GL1-GL2 dan lintasan GL3 terdapat pada kedalaman $\geq 110 \mathrm{~m}$ dengan nilai resistivitas $7-15 \Omega \mathrm{m}$ serta citra warnanya hijau. Disarankan untuk pembuatan sumur bor 1 pada titik $100 \mathrm{~m}$ diantara GL1 dan GL2 dengan kedalaman $30 \mathrm{~m}$ tepat di lapisan akuifer tertekan, dan sumur bor 2 pada titik $30 \mathrm{~m}$ dari GL3 dengan kedalaman $125 \mathrm{~m}$ [8].

Tabel 1. Hubungan jumlah lapisan, kedalaman, ketebalan nilai tahanan jenis, perkiraan lithologi dan sifat batuan terhadap air bawah tanah (Rolia, 2011).

\begin{tabular}{lclccll}
\hline & \multicolumn{5}{c}{ Hasil penafsiran } \\
\hline $\begin{array}{l}\text { Titik } \\
\text { duga }\end{array}$ & Lapisan & $\begin{array}{l}\text { kedalaman } \\
(\mathbf{m})\end{array}$ & $\begin{array}{c}\text { Tebal } \\
(\mathbf{m})\end{array}$ & $\begin{array}{c}\text { Resistivi } \\
\text { tas }(\mathbf{\Omega m})\end{array}$ & Perkiraan lithology & $\begin{array}{l}\text { Hidro- } \\
\text { geologi }\end{array}$ \\
\hline GL1 & 1 & $0-1,10$ & 1,1 & 76,14 & Lapisan lapuk & kering \\
& 2 & $1,10-6,01$ & 4,91 & 1,55 & lempung halus (silt) & Akuiklud \\
& 3 & $6,01-16,72$ & 10,71 & 37,5 & Pasir & Akuifer \\
& 4 & $16,72-129,04$ & 112,32 & 0,9 & lempung halus (silt) & Akuiklud \\
& 5 & $129,04-\infty$ & $\infty$ & 89,11 & Pasir & Akuifer \\
\hline GL2 & 1 & $0-2,17$ & 2,17 & 16,51 & Lapisan lapuk & kering \\
& 2 & $2,17-2,28$ & 0,11 & 0,02 & lempung halus (silt) & Akuiklud \\
& 3 & $2,28-16,72$ & 14,44 & 34,35 & Pasir & Akuifer \\
& 4 & $16,72-141,70$ & 124,98 & 0,16 & lempung halus (silt) & Akuiklud \\
& 5 & $141,70-\infty$ & $\infty$ & 36,05 & Pasir & Akuifer \\
\hline GL3 & 1 & $0-1,07$ & 1,07 & 81,07 & Lapisan lapuk & kering \\
& 2 & $1,07-5,53$ & 4,46 & 3,71 & lempung halus (silt) & Akuiklud \\
& 3 & $5,53-21,58$ & 16,05 & 0,84 & lempung halus (silt) & Akuiklud \\
& 4 & $21,58-107,17$ & 85,59 & 38,76 & Pasir & Akuifer \\
& 5 & $107,17-\infty$ & $\infty$ & 160,83 & Pasir & Akuifer \\
\hline
\end{tabular}






Gambar 6. Hasil interpretasi gabungan GL1, GL2, dan GL3 dengan softwere IPI2win

\section{KESIMPULAN}

Kesimpulan yang diperoleh dari hasil penelitian yang telah dilakukan adalah sebagai berikut:

1. Lapisan batuan di Desa Lok Rawa pada titik pengukuran GL1, GL2 dan GL3 pada umumnya sama yaitu terdiri dari 3 lapisan antara lain lapisan lapuk, pasir, dan lempung halus (silt).

2. Lapisan akuifer di Desa Lok rawa pada titik pengukuran GL1, GL2 dan GL3 terdapat 2 jenis lapisan akuifer yaitu lapisan akuifer bebas pada kedalaman 3-5 m, ketebalan $2 \mathrm{~m}$ dengan nilai resistivitas $7-15 \Omega \mathrm{m}$. sedangkan akuifer tertekan pada kedalaman $25-75 \mathrm{~m}$ dengan ketebalan $50 \mathrm{~m}$ dan Akuifer tertekan selanjutnya pada kedalaman $\geq 110 \mathrm{~m}$ dengan nilai resitivitasnya $7-15 \Omega \mathrm{m}$. Lapisan akuifer tertekan yang paling prospek mengandung air tanah.

\section{UCAPAN TERIMA KASIH}

Terimakasih kepada semua pihak yang telah membantu dalam penelitian ini hingga selesai.

\section{DAFTAR PUSTAKA}

[1] Suharyadi. 1984. Geohidrologi. Fakultas Teknik Universitas Gajah Mada. Yogyakarta.
[2] Hanifa, D., I. Sota., \& S.S. Siregar. 2016. Penentuan Lapisan Akuifer Air Tanah dengan Metode Geolistrik Konfigurasi Schlumberger di Desa Sungai Jati Kecamatan Mataraman Kabupaten Banjar Kalimantan Selatan. Jurnal Flux. 13(1) : 30-39.

[3] Usman, B., R.H. Manrulu., Nurfalaq., \& A.E. Rohayu. 2017. Identifikasi Akuifer Air Tanah Kota Palopo Menggunakan Geolistrik Tahanan Jenis Konfigurasi Schlumberger. Jurnal Fisika Flux. 14(2): 65-72.

[4] Winarni, E.A.T., Darsono., \& B. Legowo. 2014. Aplikasi Metode Geolistrik Resistivitas Konfigurasi Schlum-berger untuk Identifikasi Akuifer di Kecamatan Plupuh Kabupaten Sragen. Jurnal Fisika Flux. 11(2): 119-128.

[5] Hendrajaya, L., \& I. Arif. 1990. Geolistrik Tahanan Jenis. Bandung : Laboratorium Fisika Bumi Jurusan Fisika FMIPA ITB.

[6] Reynold, J.M. 1997. An introduction to Applied Geophysics. Kluwer Academic. Amerika serikat.

[7] Santoso, D. 2002. Pengantar teknik geofisika. ITB, Bandung.

[8] Jayanti, Dewi. 2015. Aplikasi Metode Geolistrik Schlumberger untuk menentukan Akuifer Air Tanah di Desa Cintapuri Kecamatan Cintapuri Darussalam Kabupaten Banjar Kalimantan Selatan. Jurusan Fisika, Fakultas Matematika dan Ilmu Pengetahuan Alam, Universitas Lambung Mangkurat, Banjarbaru.

[9] Rolia, E. 2011. Penggunaan Metode Geolistrik Untuk Mendeteksi 
Keberadaan Air Tanah. Jurnal Tapak 1(1).Nopember 2011.

[10] Wahyono, S. C, \& T. Wiyanto. 2008. Penentuan Lapisan Air Tanah dengan Metode Geolistrik
Schlumberger di Kabupaten Balangan Kalimantan Selatan. Staf Pengajar Program Studi Fisika, FMIPA, Lambung Mangkurat, Banjarbaru. 
Samsul Anwar dkk: Identifikasi Lapisan Akuifer Tertekan Dengan Metode Geolistrik Di Desa Lok Rawa Kecamatan Mandastana Kabupaten Barito Kuala Kalimantan Selatan 